precision instrument-building led to the manufacture of good seismographs. New Madrid had little, if anything, to do with these developments. The Big One is a sloppy book, based on an erroneous premise.

Naomi Oreskes is in the Department of History, University of California, San Diego,

La Jolla, California 92093-00104, USA.

\section{Population biology on the wing}

\section{On the Wings of Checkerspots: A Model System for Population Biology}

edited by Paul R. Ehrlich \& Ilkka Hanski

Oxford University Press: 2004. 371 pp.

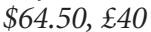

\section{Norman Myers}

Extinction is the single irreversible feature that lies at the heart of the biotic crisis overtaking the planet. But it is not the extinction of species that counts most, even though we are in the opening phase of a species extinction spasm to surpass anything since the demise of the dinosaurs and associated species 65 million years ago. More significant even than the loss of species is the extinction of populations - the discrete aggregations of individual organisms that make up species. It is populations that form the basis for the diversity and abundance of species overall. A few species comprise just one population, but most have hundreds. Worldwide there are, crudely reckoned across all species, between 1.1 billion and 6.6 billion populations. We are consigning populations to eventual extinction at a rate many times higher than that for species. This is the hidden extinction crisis, overlooked by the public and our political leaders - and it receives much less attention than it might from many biologists.

Populations also provide the ecosystem goods and services that support human economies and societies. For instance, winged insects such as butterflies and bees serve as pollinators, and disrupting this role can cause long-term cascading effects throughout ecosystems. The mass extinction of populations is propelling us into a grossly destabilized environmental future.

Because biologists can study only a very small proportion of all species and an even smaller proportion of their populations, there is a premium on identifying a few longterm field studies of populations that can shed light on key questions of evolutionary biology. Such studies have examined Galapagos finches, Gombe chimpanzees, mountain gorillas and Serengeti lions. Regrettably, there had been no such study for invertebrates until the two editors of this book, Paul

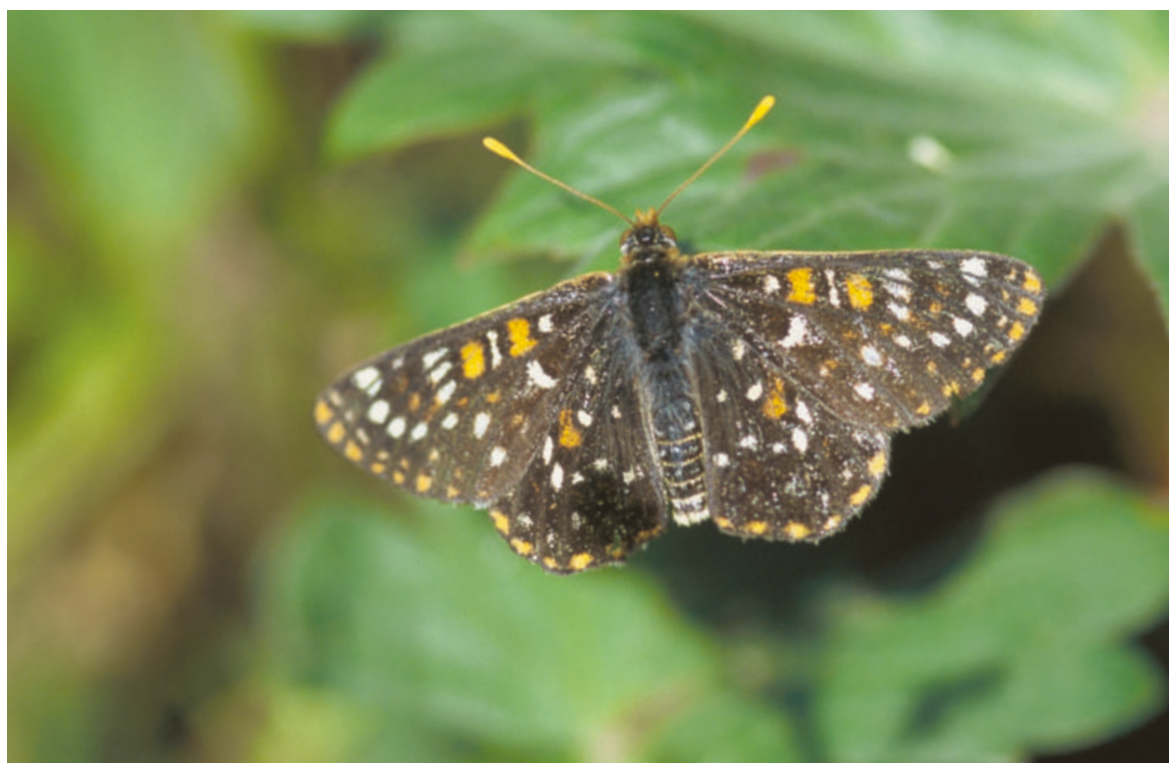

Spotting a pattern: checkerspot butterflies can help us to understand other invertebrate populations.

Ehrlich and Ilkka Hanski, started studying populations of one of the better-known categories of butterfly, the checkerspots, in central California and southern Finland.

There are at least 20,000 known butterfly species in the world, but the checkerspots make up fewer than 400 of them, and a good many of these are endangered. They are among the best-studied populations of all invertebrates, and so are crucial for our understanding of the millions of invertebrates that make up the vast majority of all species. The two editors and 13 contributing researchers have sought to use their 40-plus years of intensive field and laboratory study "to create one population biological analogue to the well-known model systems in other biological disciplines, such as the fruitflies of classical genetics". The result is a collaborative overview of model systems in population studies.

The book reviews a spectrum of the basic biology of checkerspots, including reproductive and larval biology, feeding patterns, population structure and dynamics, ecology and taxonomy. There are extended discussions of such issues as dispersal and migration, colonization, inbreeding depression, predation and parasitism, genetic differentiation, habitat fragmentation, threshold disturbances (especially by humans), climate and conservation biology. To cite the editors' ultimate purpose, the major intellectual challenge of population biology "is understanding the functioning of natural populations - how they are distributed and structured, how and why their sizes change, and how they evolve". In many respects, the book offers basic insights into the ecological and evolutionary dynamics of insect populations generally, not just of checkerspots, and thus forms a classic of modern biology.

The book provides lots of lessons for conservation biology. Many butterflies occupy successional habitats, which are in transition from one ecological state to another. So studying their populations indicates how far they can adapt their lifestyles to humandisturbed landscapes. Like many butterfly species, checkerspots favour open country. Humans have been a potent force in converting forests into open landscapes, but regrettably many of these are pesticidedoused farmlands, overgrazed pastures, golf courses and treeless subdivisions - far from suitable habitats for butterflies.

Butterflies are a staple of summer gardens, parks and other landscapes. Yet about one-fifth of European butterfly species are threatened or vulnerable, and roughly oneseventh of those in the United States and Canada are at risk in certain areas or in the whole of their ranges. The path towards extinction can be rapid. The large blue butterfly (Maculinea arion) in Britain declined from some 30 populations with an estimated 100,000 individuals in the mid-1950s to just a single population of only 250 adults in the early 1970s, and to final extinction in 1979. Conversely, several UK butterfly species have expanded their ranges in recent years, ostensibly in response to global warming.

In the main, however, the prospect for many butterflies is not propitious. This book offers many clues on how we can improve that prospect.

Norman Myers is honorary visiting fellow at Green College, Oxford University, Upper Meadow, Old Road, Oxford OX3 8SZ, UK.

\section{Correction}

In Benno Müller-Hill's review of the book on Adolf Butenandt (Nature 431, 246; 2004), it was wrongly claimed that Otmar von Verschuer told colleagues in 1946 of his and Gunter Hillman's involvement in the analysis of blood samples from Auschwitz. In fact, von Verschuer disclosed this information in a written report to the DFG in 1944. 